See discussions, stats, and author profiles for this publication at: https://www.researchgate.net/publication/326598322

\title{
Rational beliefs, happiness and optimism: An empirical assessment of REBT's model of psychological health
}

Article in International Journal of Psychology · July 2018

DOI: 10.1002/ijop.12492

\section{CITATIONS}

4 authors:

Horea-Radu Oltean

Babeş-Bolyai University

9 PUBLICATIONS 27 CITATIONS

SEE PROFILE

(9.) Frédérique Vallières

Trinity College Dublin

64 PUBLICATIONS 387 CITATIONS

SEE PROFILE

Some of the authors of this publication are also working on these related projects:

Project $\quad$ REBT and CBT in Depression View project

Project ACCESS TO INFANT AND MATERNAL HEALTH - AIM HEALTH View project
8 Philip Hyland

181 PUBLICATIONS 2,242 CITATIONS

SEE PROFILE

Daniel David

Babeş-Bolyai University

328 PUBLICATIONS 8,454 CITATIONS

SEE PROFILE 


\title{
Rational beliefs, happiness and optimism: An empirical assessment of REBT's model of psychological health
}

\author{
Horea-Radu Oltean ${ }^{1,2}$, Philip Hyland ${ }^{3,4}$, Frédérique Vallières ${ }^{4}$, \\ and Daniel Ovidiu David ${ }^{2,5}$ \\ ${ }^{1}$ Doctoral School "Evidence-based assessment and psychological interventions", Babes-Bolyai \\ University, Cluj-Napoca, Romania \\ ${ }^{2}$ The International Institute for the Advanced Studies of Psychotherapy and Applied Mental \\ Health, Babeş-Bolyai University, Cluj-Napoca, Romania \\ ${ }^{3}$ National College of Ireland, Dublin, Ireland \\ ${ }^{4}$ Centre for Global Health, Trinity College Dublin, Dublin, Ireland \\ ${ }^{5}$ Icahn School of Medicine at Mount Sinai, New York, NY, USA
}

\begin{abstract}
7 his study sought to test the validity of the psychological health model of Rational Emotive Behaviour Therapy (REBT). Specifically, this study sought to investigate if rational beliefs were associated with happiness and optimism. A multinational sample of 397 university students completed self-report measures of rational beliefs, happiness and optimism. Structural equation modelling (SEM) was used in order to test the validity of the REBT model of psychological health. The result of the SEM analysis provided empirical support for REBT's psychological health model of happiness and optimism. The model as a whole explained 33\% of variance in levels of happiness and $40 \%$ of variance in levels of optimism. Self-acceptance beliefs were positively and directly associated with happiness and optimism. Preference beliefs were positively and indirectly associated with happiness and optimism via self-acceptance beliefs. REBT may offer a viable psychotherapeutic method to not only alleviate psychological distress, but also build positive emotion. Current findings may help to bridge the divide between the fields of positive psychology and clinical psychology.
\end{abstract}

Keywords: Rational emotive behaviour therapy; Irrational beliefs; Rational beliefs; Anxiety and depression; Subjective well-being; Happiness; Optimism; Positive psychology.

Two of the most commonly studied constructs in the field of positive psychology are happiness and optimism (Snyder \& Lopez, 2009). In a comprehensive review of cross-sectional, longitudinal and experimental findings, Lyubomirsky, King, and Diener (2005) demonstrated that happiness is correlated with, predictive of, and causally determinative of success in multiple domains of life including social, relational, financial, work and (mental and physical) health domains. Given the importance of happiness, and positive affect more broadly, much work has been undertaken to understand factors associated with happiness. At an individual and societal level, happiness tends to be most strongly correlated with the quality of personal relationships, income, age, education, personality, health, work-related variables, optimism, freedom, autonomy and social status. One psychological factor that has received little empirical attention as a correlate of happiness is a person's habitual thinking style (Robinson \& Eid, 2017).

Rational Emotive Behaviour Therapy (REBT, Ellis, 1994) is one of the first forms of cognitive-behaviour therapy (CBT) and it is distinguished from the other CBT schools by its assumption that the proximal cause of emotions are evaluative cognitions (David \& Cramer, 2009).

Correspondence should be addressed to Horea-Radu Oltean, The International Institute for the Advanced Studies of Psychotherapy and Applied Mental Health, Babeş-Bolyai University, No. 37, Republicii Street 37, 400015 Cluj-Napoca, Romania. (E-mail: horea.oltean@ubbonline.ubbcluj.ro)

First and second authors designed the study. Second author collected data and conducted the statistical analyses. First author wrote the first draft of the manuscript. Second, third and fourth authors revised critically the manuscript, contributed at interpretation of data and all authors contributed to and have approved the final manuscript. Authors, Horea-Radu Oltean, Philip Hyland, Frédérique Vallières, and Daniel Ovidiu David have no conflict of interest with respect to this publication. This paper is a result of a research made possible by the financial support of the Sectoral Operational Programme for Human Resources Development 2007-2013, co-financed by the European Social Fund, under the project POSDRU/187/1.5/S/155383"Quality, excellence, transnational mobility in doctoral research". 
REBT states that emotions are not directly determined by life events, but rather by how these events are evaluated (David, Lynn, \& Ellis, 2009; Ellis, 1994). REBT theory assumes that various activating events prime specific beliefs, which in turn will cause the emotional response. According to REBT, there are two main ways in which a person can evaluate an event; rationally or irrationally. Irrational beliefs are those cognitions which do not have logical, pragmatic and/or empirical support (David \& Cramer, 2009). There is a large body of research that demonstrates strong associations between irrational beliefs and several negative dysfunctional affective outcomes or maladaptive behaviours (David, 2015; Vîslă, Flückiger, Grosse Holtforth, \& David, 2016). This is known as the REBT model of psychopathology. Rational beliefs are those cognitions which are have logical, pragmatic and/or are empirical supportable (David \& Cramer, 2009). There is a growing body of research showing that rational beliefs are negatively associated with dysfunctional affective outcomes (Hyland, Maguire, Shevlin, \& Boduszek, 2014; Oltean, Hyland, Vallières, \& David, 2017). This is known as the REBT model of psychological health.

The REBT model of psychological health states that not only should the presence of rational belief mitigate the onset of distressing negative emotional states, but also that rational beliefs should also give rise to functional emotions, which in turn may favor the appearance of positive emotional and behavioural outcomes. To the best of our knowledge, there are only two studies that have investigated the relationship between rational beliefs and positive life outcomes (Balkis, 2013; Balkis, Duru, $\&$ Bulus, 2012). These studies found weak-to-moderate correlations ( $r$ ranging from .25 to .33 ) between rational beliefs and academic life satisfaction and academic achievement. To date, no empirical assessments of the relationship between rational beliefs and positive emotional constructs such as happiness and optimism have been assessed.

The primary goal of this study was therefore to undertake the first empirical assessment of the REBT model of psychological health in the context of understanding feelings of happiness and levels of optimism. Using structural equation modelling (SEM) procedures, we hypothesised that: (a) the REBT model of psychological health would be a satisfactory model to understand happiness and optimism and (b) that rational beliefs would be directly, and indirectly, associated with both happiness and optimism.

\section{METHOD}

\section{Participants and procedures}

The sample for the current study consisted of undergraduate psychology and computer science students recruited from four universities in the Republic of Ireland, Northern Ireland and England $(N=397)$. The sample included a similar number of men $(n=191,49.6 \%)$ and women $(n=194,50.4 \%)$ with an average age of 23.33 years $(S D=7.91$, range $18-60)$. Students had spent on average 2.23 years in university $(S D=1.20$, range $0-7)$ at the time of assessment. The majority of students lived in urban or suburban environments $(n=252,65.7 \%)$ and were single $(n=315,82 \%)$. All participants were selected in an opportunistic fashion and data was collected during the academic calendar from September 2013 to May 2014. Ethical approval was obtained from the ethical review board at the institution to which one of the authors belongs. All students under the age of 18 were excluded from the study. Participants were assured of confidentiality, instructed that they were under no obligation to participate, and could withdraw at any time. Participants completed questionnaires using a paper-and-pencil format in their regular lecture/laboratory setting. No inducements or incentives (e.g., course credit) were used to recruit volunteers.

\section{Measures}

The Attitudes and Belief Scale 2-Abbreviated Version (ABS-2-AV: Hyland, Shevlin, Adamson, \& Boduszek, 2014) is a 24-item self-report measure of rational and irrational beliefs consistent with contemporary REBT theory (Ellis, 1994). The ABS2-AV measures four irrational belief processes (demandingness, catastrophising, low frustration intolerance and self-downing beliefs) and four rational belief processes (preferences, realistic evaluations of badness, high frustration tolerance and self-acceptance). According to the REBT theory, preference is considered the primary appraisal mechanism, while realistic evaluation of badness, high frustration tolerance, and self-acceptance are secondary appraisal mechanisms (see Fig. 1). For the purposes of the current study only the 12 items measuring the rational beliefs were of interest. Each rational belief is measured via three items and all items are scored along a 5-point Likert-scale from 1 ("Strongly Disagree") to 5 ("Strongly Agree"). Higher scores in each case indicate greater endorsement of a given belief process. Previous psychometric assessments of the ABS2-AV suggested that the questionnaire possesses satisfactory factorial validity and internal reliability (Hyland, Maguire, et al., 2014; Oltean et al., 2017). Among the current sample, reliability estimates (Cronbach's alpha) for the four rational belief processes were mixed, $(\mathrm{PRE}=.74 ; \mathrm{REB}=.36$; $\mathrm{HFT}=.52$ and $\mathrm{UA} / \mathrm{SA}=.77$ ) with the reliably for the realistic evaluations of badness subscale being very low.

The Oxford Happiness Questionnaire (OHQ: Hills $\&$ Argyle, 2002) was used to capture feelings of happiness. The OHQ is an 8-item scale derived from 
the 29-item Oxford Happiness Inventory. The OHQ items are scores on a six-point Likert scale ranging from 1 ("Strongly Disagree") to 6 ("Strongly Agree") with higher score reflecting higher levels of happiness. The OHQ has been shown to be highly correlated with the OHI, to possess excellent convergent and discriminant validity, and explained in terms of a single unidimensional model (Hills \& Argyle, 2002). The internal reliability of the OHQ within the current sample was satisfactory (Cronbach's alpha $=.73$ ).

Optimism was measured using the Revised Life Orientation Test (LOT-R: Scheier, Carver, \& Bridges, 1994). The LOT-R is the most commonly used measure of optimism and contains 10 items; 4 test/filler items and 6 items used to measure optimism. Three of these items are phrased positively (optimism) and three are phrased negatively (pessimism). Multiple psychometric studies utilising large nationally representative samples indicate that the LOT-R measures two weakly correlated factors: optimism and pessimism (e.g., Glaesmer et al., 2012). All items of the LOT-R are scored on a 1 ("Disagree a lot") to 5 ("Agree a lot") Likert scale. The internal reliabilities for the optimism and pessimism subscales for the current sample were .66 and .81 , respectively.

\section{Data analysis}

SEM was used to test the REBT psychological health model of happiness and optimism (see Figure 1). SEM is a combination of two analytical procedures: confirmatory factor analysis (CFA), which assesses the measurement component of a theoretical model, and path analysis, which assesses the relationships between latent variables within the model. A number of features make the use of SEM appropriate for the current analysis and these include: (a) the ability to control for random measurement error and thus improve the reliability of results, (b) the ability to test the congruence between the hypothesised model structures and the sample data therefore allowing falsification of the proposed model structures and (c) the ability to simultaneously test for direct, indirect and total effects between variables in the model (Kline, 2011). A two-stage modelling procedure was conducted. First, the validity of the measurement models were established, followed by an assessment of the structural models.

In order to test the validity of the measurement and structural components of each model, standard recommendations for determination of model fit were followed (Kline, 2011). A chi-square-to-degrees of freedom $(\chi 2: d f)$ ratio of less than 3:1 suggests good model fit; Comparative Fit Index (CFI) and Tucker Lewis Index (TLI) values greater than .90 reflect acceptable model fit, and values greater than .95 reflect excellent fit;

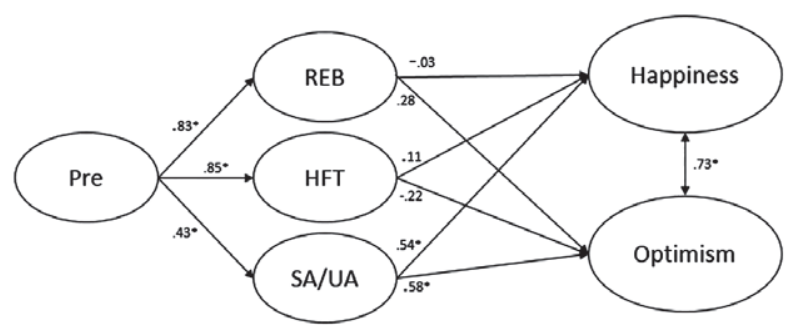

Figure 1. REBT psychological health model of happiness and optimism: Pre $=$ Preference beliefs; REB $=$ Realistic Evaluations of Badness; HFT = High Frustration Tolerance; SA/UA = Self-Acceptance; * indicate path is statistically significant $(p<.01)$.

Root-Mean-Square Error of Approximation with 90\% confidence intervals (RMSEA 90\% CI) and Standardised Root-Mean-Square Residual (SRMR) values of 0.05 or less reflect excellent model fit, while values less than 0.08 reflect acceptable fit.

In order to test for indirect effects, we followed the recommendations of Preacher and Hayes (2008) and used bias-corrected (BC) bootstrapping techniques. Bootstrapping is a non-parametric resampling technique that does not assume multivariate normality of the sampling distribution, and allows for the production of confidence intervals around the observed indirect effects. To produce confidence intervals for the indirect effects in the current study 1000 bootstrap samples were used. All analyses were conducted in Mplus version 7.0. The CFA procedures were estimated using Robust Maximum Likelihood (MLR) estimation (Yuan \& Bentler, 2000), however, for the SEM analyses Maximum Likelihood estimation was used as the MLR estimator cannot be used when applying bootstrapping techniques.

\section{RESULTS}

\section{Descriptive statistics}

Measures of central tendency and variability for all variables in this study are displayed in Table 1 . The current sample reported moderate levels of each of the rational beliefs with the exception of UA/SA beliefs which were high. Happiness and optimism levels were both moderate-to-high.

\section{Measurement model of happiness (OHQ)}

A unidimensional model of the OHQ, suggested by Hills and Argyle (2002), was assessed using CFA. Results suggested that the unidimensional model of happiness provided acceptable fit: $\left(\chi^{2}=63.11, d f=20, p<.001\right.$; $\mathrm{CFI}=.91 ; \mathrm{TLI}=.88 ; \mathrm{RMSEA}=.07[95 \% \mathrm{CI}=.05-.10]$; SRMR =.04). The standardised factor loadings for each item were all positive and statistically significant 
TABLE 1

Descriptive statistics for all variables in the study

\begin{tabular}{|c|c|c|c|c|}
\hline & $\begin{array}{c}\text { Mean } \\
\text { (95\% Confidence } \\
\text { Intervals) }\end{array}$ & Median & SD & Range \\
\hline Preferences & $9.35(9.09-9.62)$ & 9.00 & 2.60 & $3-15$ \\
\hline REB & $11.06(10.87-11.26)$ & 11.00 & 1.93 & $5-15$ \\
\hline HFT & $10.31(10.08-10.53)$ & 11.00 & 2.25 & $3-15$ \\
\hline Self-acceptance & $11.95(11.69-12.22)$ & 12.00 & 6.98 & $3-15$ \\
\hline Happiness & $32.88(32.21-33.54)$ & 33.50 & 6.64 & $12-47$ \\
\hline Optimism & $10.47(10.20-10.74)$ & 11.00 & 2.68 & $3-15$ \\
\hline
\end{tabular}

Note $:$ LFT = Low Frustration Tolerance; REB = Realistic Evaluations of Badness; HFT $=$ High Frustration Tolerance; $S W L=$ Satisfaction with Life; $\mathrm{SD}=$ standard deviation.

$(\mathrm{p}<.001)$. Two items $(5$, and 8) demonstrated weak factor loadings (.24 and .23, respectively). All other factor loadings were greater than .40 and the mean factor loading for the eight items was .51.

\section{Measurement model of optimism (LOT-R)}

To assess the latent structure of the LOT-R we compared a unidimensional model (six items loading onto one factor) to the empirically supported two-factor model (three items loading onto an Optimism factor, and three items loading onto a Pessimism factor). Consistent with previous findings, the two-factor model $\left(\chi^{2}=16.58\right.$, $d f=8, p=.04 ; \mathrm{CFI}=.98 ; \mathrm{TLI}=.97 ; \mathrm{RMSEA}=.05[95 \%$ $\mathrm{CI}=.01-.09]$; $\mathrm{SRMR}=.03$ ) demonstrated superior fit to the one-factor model $\left(\chi^{2}=53.34, d f=9, p<.001\right.$; $\mathrm{CFI}=.92 ; \mathrm{TLI}=.86 ; \mathrm{RMSEA}=.11[95 \% \mathrm{CI}=.09-.14]$; SRMR $=.05)$. The three optimism items loaded onto the Optimism factor positively, and significantly $(p<.001)$, with a mean factor loading of .63. This factor was thus retained for inclusion with the full structural model.

\section{Measurement model of rational beliefs}

CFA was applied in order to determine if the four latent rational belief variables (preferences, realistic evaluations of badness, high frustration tolerance and self-acceptance) were adequately measured via their respective items from the ABS2-AV. The fit of this model to the data was generally acceptable $\left(\chi^{2}=108.16\right.$, $d f=48, p<.001 ; \mathrm{CFI}=.92 ; \mathrm{TLI}=.89 ; \mathrm{RMSEA}=.06$ [95\% CI $=.04-.07]$; SRMR $=.05$ ); however, inspection of the MI results indicated that a considerable residual covariance existed between one item intended to measure Realistic Evaluations of Badness beliefs ("When life is hard and I feel uncomfortable, I realize it is not awful to feel uncomfortable or tense, only unfortunate and I can keep going"), and one item intended to measure High Frustration Tolerance beliefs ("I do not like to be uncomfortable, tense or nervous, but I can tolerate being tense"). The high residual covariance between these two items was understandable in light of the fact that both items present the respective rational beliefs in the context of being uncomfortable. The decision was made to re-specify the measurement model with the inclusion of a residual covariance between the two items. This re-specified model produced satisfactory fit statistics $\left(\chi^{2}=88.53, d f=47, \quad p<.001 ; \quad\right.$ CFI $=.95 ; \quad$ TLI $=.93 ;$ RMSEA $=.05$ [95\% CI =.03-.06]; SRMR =.04). The standardised factor loadings for each item were all positive, statistically significant $(p<.01)$, and ranged from .24 to .82 .

\section{Structural model: The REBT model of psychological health}

The REBT psychological health model predicting happiness and optimism (see Figure 1) provided an acceptable fit of the sample data $\left(\chi^{2}=407.54, d f=219, p<.001\right.$; $\mathrm{CFI}=.91 ; \mathrm{TLI}=.90 ; \mathrm{RMSEA}=.05[95 \% \mathrm{CI}=.04-.05]$; SRMR $=.06)$ and explained $33 \%$ of variance in happiness levels, and $40 \%$ of variance in optimism levels.

Parameter estimates indicated that Preference beliefs positively predicted realistic evaluations of badness $(\beta=.83, p=.002)$, high frustration tolerance $(\beta=.85$, $p=.015)$ and self-acceptance $(\beta=.43, p<.001)$ beliefs. Self-acceptance beliefs positively, robustly and significantly predicted happiness $(\beta=.54, p<.001)$ and optimisms $(\beta=.58, p<.001)$. Neither realistic evaluations of badness nor high frustration tolerance beliefs predicted levels of happiness and optimism. A positive, statistically significant indirect effect was observed between preference beliefs and happiness via self-acceptance beliefs $(\beta=.23, S E=.06,95 \%$ CI $[\mathrm{BC}]=.12-.34, p<.001)$. Additionally, a positive, statistically significant indirect effect was also observed between preference beliefs and optimism via self-acceptance $(\beta=.25, S E=.06,95 \% \mathrm{CI}$ $[\mathrm{BC}]=.14-.36, p<.001)$.

\section{DISCUSSION}

The current study was conducted to provide the first assessment of the REBT model of psychological health to predict happiness and optimism. The SEM findings were consistent with the predictions of REBT theory, in that the model of psychological health was found to provide a good representation of happiness and optimism. Moreover, the model explained a substantial proportion of variance in both happiness $(33 \%)$ and optimism $(40 \%)$ scores. Consistent with the study's second hypothesis, the rational beliefs were found to be directly and indirectly associated with happiness and optimism. Specifically, those higher in self-acceptance beliefs experienced higher levels of happiness and optimism. Those scoring higher in preference beliefs also reported 
higher levels of happiness, due in part, seemingly, to their higher levels of self-acceptance beliefs. The central role of self-acceptance beliefs in predicting levels of happiness and optimism can likely be explained by their non-judgmental nature. It is possible that greater flexibility and acceptance of oneself may lead to positive evaluations of life events in general. This could in turn foster more positive emotions (happiness) and more positive expectations (optimism).

These findings have important theoretical and clinical significance. From a theoretical perspective the current findings add to a growing literature attesting to the validity of the REBT model of psychological health. While previous studies have shown that rational beliefs act as cognitive protective factors against negative psychological experiences such as depression, anxiety and post-traumatic stress symptoms (Hyland, Shevlin, et al., 2014; Oltean et al., 2017), current findings indicate that these same cognitive processes are positively associated not only with negative functional emotions, but also with positive psychological experiences. These findings also contribute to the wider positive psychology literature given that, to date, cognitive correlates of positive emotions have received little empirical assessment, with some notable exceptions (see Robinson \& Eid, 2017). The focus of the research in the field has traditionally centred on the role of personality, socio-economic, inter-personal, work-related and genetic factors (Forgeard \& Seligman, 2012; Veenhoven, 2015). Current evidence suggests that functional cognitions may also play an important role in the prediction of positive mental health states.

A recent meta-analysis (Bolier et al., 2013) investigated the efficacy of positive psychology interventions. The results showed a small average effect sizes $(d=.23$ for depression and $d=.34$ for subjective well-being). These results suggest that, in spite of the fast development of the field of positive psychology, its clinical derivatives have not managed to generate significant improvements for the clinical field. Therefore, the results of the present study may be seen as offering a way to bridge the gap between the fields of clinical and positive psychology. Given the fact that rational beliefs are negatively associated with negative mental health states (David, 2015; Hyland, Maguire, et al., 2014; Oltean \& David, in press) and, at same time, are positively associated with positive mental health states such as happiness and optimism, clinical work could potentially be simplified by focusing attention on rational beliefs, and thereby modulating positive and negative emotions simultaneously.

The current study is limited by virtue of the non-representativeness of the sample meaning that the generalisability of the current findings is questionable. Furthermore, the cross-sectional nature of the study, and the measurement issues associated with some subscales of the ABS2-AV means that these results should be interpreted with caution. In order to better determine whether rational beliefs are predictive of happiness and optimism, longitudinal and experimental studies should be undertaken. Current findings of an association between rational beliefs and positive emotional states is, however, an important prerequisite for testing temporal and causal relationships.

In conclusion, the findings of the current study indicate for the first time that the REBT model of psychological health is applicable in the context of positive emotional experiences. Preferential beliefs and self-acceptance beliefs appear to be particularly relevant for both happiness and optimism indicating good targets for clinical interventions. REBT, as an established and empirically supported clinical approach, may offer a viable way in which to bridge the fields of clinical and positive psychology with its therapeutic targets being rational and irrational beliefs that are associated with both negative and positive emotional experiences.

Manuscript received February 2017 Revised manuscript accepted March 2018

\section{REFERENCES}

Balkis, M. (2013). Academic procrastination, academic life satisfaction and academic achievement: The mediation role of rational beliefs about studying. Journal of Cognitive and Behavioral Psychotherapies, 13(1), 57-74.

Balkis, M., Duru, E., \& Bulus, M. (2012). Analysis of the relation between academic procrastination, academic rational/irrational beliefs, time preferences to study for exams, and academic achievement: A structural model. European Journal of Psychology of Education, 28(3), 825-839. https:// doi.org/10.1007/s10212-012-0142-5

Bolier, L., Haverman, M., Westerhof, G. J., Riper, H., Smit, F., \& Bohlmeijer, E. (2013). Positive psychology interventions: A meta-analysis of randomized controlled studies. BMC Public Health, 13(1), 1-20. https://doi.org/10.1186/1471-2458-13119

David, D. (2015). Rational emotive behavior therapy (REBT). In R. L. Cautin \& S. O. Lilienfeld (Eds.), Encyclopedia of clinical psychology. Wiley Blackwell: Hoboken, NJ.

David, D., \& Cramer, D. (2009). Rational and irrational beliefs in human feelings and psychophysiology. In D. David, S. J. Lynn, \& A. Ellis (Eds.), Rational and irrational beliefs: Research, theory, and clinical practice. New York, NY: Oxford University Press, Inc.

David, D., Lynn, S. J., \& Ellis, A. (2009). Rational and irrational beliefs: Research, theory, and clinical practice. New York, NY: Oxford University Press, Inc.

Ellis, A. (1994). Reason and emotion in psychotherapy. New Jersey: Carol Publishing Group.

Forgeard, M. J. C., \& Seligman, M. E. P. (2012). Seeing the glass half full: A review of the causes and consequences of optimism. Pratiques Psychologiques, 18(2), 107-120. https://doi.org/10.1016/j.prps.2012.02.002

Glaesmer, H., Rief, W., Martin, A., Mewes, R., Brähler, E., Zenger, M., \& Hinz, A. (2012). Psychometric properties and population-based norms of the life orientation test 
revised (LOT-R). British Journal of Health Psychology, 17(2), 432-445.

Hills, P., \& Argyle, M. (2002). The Oxford happiness questionnaire: A compact scale for the measurement of psychological well-being. Personality and Individual Differences, 33(7), 1073-1082.

Hyland, P., Maguire, R., Shevlin, M., \& Boduszek, D. (2014). Rational beliefs as cognitive protective factors against posttraumatic stress symptoms. Journal of Rational-Emotive \& Cognitive-Behavior Therapy, 32(4), 297-312.

Hyland, P., Shevlin, M., Adamson, G., \& Boduszek, D. (2014). Modeling the structure of the attitudes and belief scale 2 using CFA and bifactor approaches: Toward the development of an abbreviated version. Cognitive Behaviour Therapy, 43(1), 60-71. https://doi.org/10.1080/16506073.2013 .777467

Kline, R. B. (2011). Principles and practice of structural equation modeling. New York, NY: Guilford Press.

Lyubomirsky, S., King, L., \& Diener, E. (2005). The benefits of frequent positive affect: Does happiness lead to success? Psychological Bulletin, 131(6), 803-855. https://doi.org/10 .1037/0033-2909.131.6.803

Oltean, H. R., \& David, D. O. (2018). A meta-analysis of the relationship between rational beliefs and psychological distress. Journal of Clinical Psychology, 74(6), 883-895. https://doi.org/10.1002/jclp.22562

Oltean, H.-R., Hyland, P., Vallières, F., \& David, D. O. (2017). An empirical assessment of REBT models of psychopathology and psychological health in the prediction of anxiety and depression symptoms. Behavioural and Cognitive Psychotherapy, 45, 1-16. https://doi.org/10.1017/ S1352465817000133

Preacher, K. J., \& Hayes, A. F. (2008). Asymptotic and resampling strategies for assessing and comparing indirect effects in multiple mediator models. Behavior Research Methods, 40(3), 879-891. https://doi.org/10.3758/BRM.40.3.879

Robinson, M. D., \& Eid, M. (2017). The happy mind: Cognitive contributions to well-being. Cham, Switzerland: Springer.

Scheier, M. F., Carver, C. S., \& Bridges, M. W. (1994). Distinguishing optimism from neuroticism (and trait anxiety, self-mastery, and self-esteem): A reevaluation of the life orientation test. Journal of Personality and Social Psychology, 67(6), 1063-1078.

Snyder, C. R., \& Lopez, S. J. (2009). Oxford handbook of positive psychology. New York, NY: Oxford University Press.

Veenhoven, R. (2015). Social conditions for human happiness: A review of research. International Journal of Psychology, 50(5), 379-391. https://doi.org/10.1002/ijop.12161

Vîslă, A., Flückiger, C., Grosse Holtforth, M., \& David, D. (2016). Irrational beliefs and psychological distress: A meta-analysis. Psychotherapy and Psychosomatics, 85(1), 8-15. https://doi.org/10.1159/000441231

Yuan, K.-H., \& Bentler, P. M. (2000). Three likelihood-based methods for mean and covariance structure analysis with nonnormal missing data. Sociological Methodology, 30(1), 165-200. https://doi.org/10.1111/0081-1750.00078 